\title{
The swimmer's nose clip in epistaxis
}

\author{
Philip Turner
}

\begin{abstract}
A swimmer's nose clip applies constant pressure on the bleeding area in epistaxis and can be left in place for as long as necessary without excessive discomfort. ( $\mathcal{F}$ Accid Emerg Med 1996;13:134)
\end{abstract}

Key terms: swimmer's nose clip; epistaxis

The initial treatment of spontaneous epistaxis is to pinch the nostrils together to apply local pressure to the bleeding vessels. ${ }^{1}$ The aim is to either stop the bleeding completely or to reduce it sufficiently to enable accurate visualisation followed by chemical or thermal cautery. Traditionally, pinching the nose has been done by the patients themselves, but requires adequate explanation about where to apply the pressure, how much, and for how long. Alternatively an assistant can do this, but if it has to be a member of staff, they are occupied for up to 30 minutes unless an alternative method can be found.

A swimmer's nose clip (fig 1) of the correct design is available from many shops and leisure

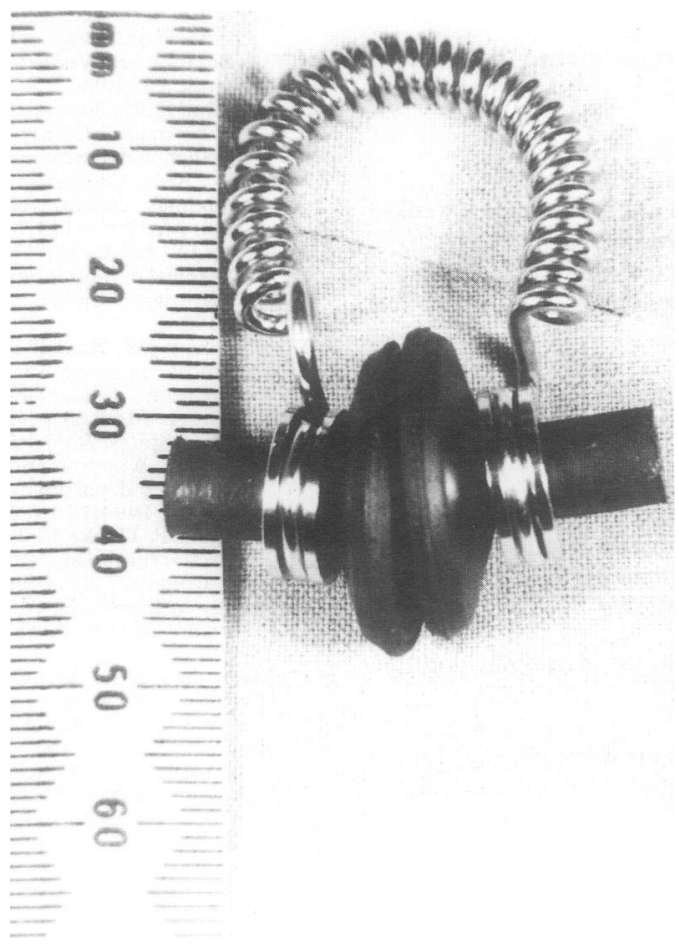

Figure 1 The most frequently used type of clip for swimming is the most efficient in epistaxis control.

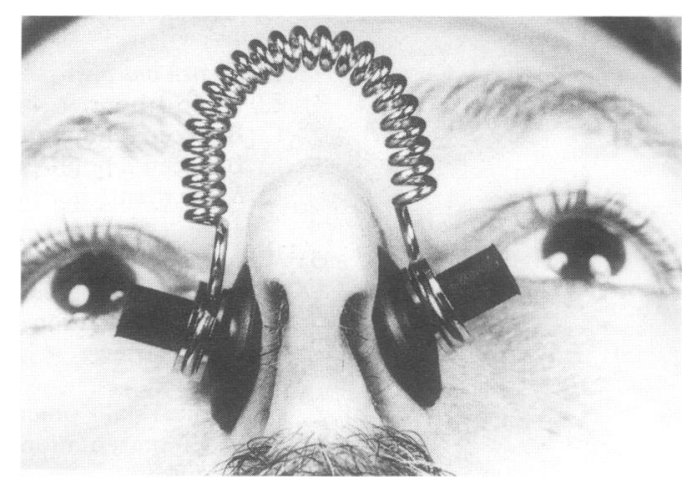

Figure 2 The nose clip in position.

centres, and if applied accurately (fig 2), puts a constant pressure on precisely the area that is bleeding. It can be left in place for as long as necessary without causing too much discomfort, does not cause the finger aching so common after manual compression, and requires minimal monitoring. The clip is equally effective in children and adults, and is readily accepted by the younger patient. Additional pressure can be applied by inserting a pledget of cotton wool or gauze into the nares before application, which can be soaked in local anaesthetic or other solution if preferred.

It is not recommended that the clip be applied in epistaxis following head trauma, but is ideal for the majority of patients with bleeding from the vessels under Little's area. This accounts for the bulk of cases of nontraumatic epistaxis presenting to $A \& E .^{2}$ In recurrent cases, patients can be advised how to apply the clip, and most are then quite happy to buy their own, use it when needed, and only attend hospital when bleeding cannot be stopped in spite of adequate pressure for sufficient time. The clips are made of metal and rubber, and are easily disinfected in the hospital HSDU. One size usually fits all ages.

I believe this piece of equipment can do the job in most circumstances better than a patient or assistant, and is cheap enough (less than $£ 5$ ) to be a very useful addition to any $A \& E$ department or general practitioner's bag.

1 Berkow R, ed. The Merck manual of diagnosis and therapy, 16th ed. 1992:2344.

2 Maran AGD \& Stell PM. Clinical otolaryngology. Oxford: Blackwell 1979:208. 